\title{
Hypertrophy of heart with outflow tract obstruction and myocardial necrosis in an infant with multiple congenital malformations
}

\author{
R. Yarom and K. Fried \\ From the Departments of Pathology and Genetics, \\ The Hebrew University-Hadassah Medical School, ferusalem
}

A case of cardiac hypertrophy with obstruction of both outflow tracts, myocardial necrosis, and an apical aneurysm in a newborn infant is described. There were also congenital anomalies in the brain, kidneys, and lungs.

The rarity of this particular heart anomaly in a newborn is stressed, and its possible pathogenesis discussed.

Congenital ventricular septal hypertrophy causing both aortic and pulmonary outflow tract obstruction is very rare in infancy (Neufeld, Ongley, and Edwards, 1960). Its association with myocardial infarction and aneurysm formation has not been, to our knowledge, previously reported.

In a recent necropsy of a full-term newborn baby with multiple congenital anomalies, a much enlarged heart with the above-mentioned anomalies was encountered.

\section{Case report}

Family history The parents are both Jews born in Baghdad and are not related. They are both healthy and there are no heart or kidney diseases in the family. The mother was 25 and the father 31 years old at the time of this birth. There were 5 previous pregnancies; 3 normal boys are now alive and well. The second pregnancy was terminated by a breech delivery of a stillborn hydrocephalic male baby; in the third pregnancy, during the eighth month, a large foetal head was discovered by palpation and a diagnosis of hydrocephalus was confirmed radiologically. After withdrawing $350 \mathrm{ml}$. cerebrospinal fluid through a fontanellar puncture, a male premature infant was delivered vaginally and died soon afterwards. No necropsies were performed on either of the babies.

Present case This was the mother's sixth pregnancy during which she was well. At term a breech presentation was found and hydrocephalus was again suspected both clinically and radiologically. A lower segment caesarian section resulted in delivery of a $3600 \mathrm{~g}$. girl. The baby did not breathe spontaneously and had to be resuscitated. The ears were low set and dysplastic. The heart was enlarged and a systolic murmur was heard all over the praecordium; the pulse rate was slow, below a hundred a minute; the liver and spleen were enlarged suggesting congestive heart failure. The infant died one hour after birth.

Necropsy findings Multiple congenital abnormalities were found consisting of the following. Severe internal hydrocephalus with an absent roof of the fourth ventricle and an arachnoid cerebellar cyst (Dandy-Walker syndrome); bilateral dysplasia and hypoplasia of the kidneys; and absent middle lobe of the right lung.

Of special interest were the findings in the heart which was much enlarged, weighing $50 \mathrm{~g}$., with hypertrophy of all the chambers, the interventricular septum being especially prominent and $2 \mathrm{~cm}$. in thickness. It impinged obviously on the outflow tracts of both right and left ventricles causing a subaortic and infundibular pulmonary stenosis (Fig. I). At the apex and at the lower anterior part of the left ventricle the myocardium became gradually thinned out and bulged forwards in an aneurysm with a wall $2 \mathrm{~mm}$. thick and a capacity of about $3 \mathrm{ml}$. On microscopical examination the thinnest part consisted of collagenous connective tissue while in the junctional areas hypertrophied muscle fibres were interspersed with fibrous tissue, patches of fresh muscle necrosis, and areas rich in thin-walled blood vessels and histocytic cells, the picture of an organizing infarction (Fig. 2). Additional microscopical changes occurred in the papillary muscles 


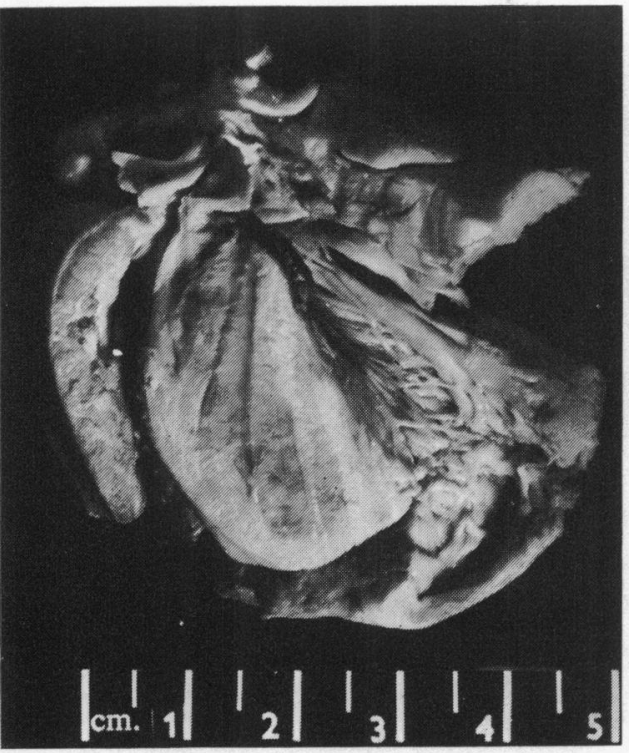

FI G. I The heart showing generalized hypertrophy and the very thick septum obstructing the right and left outflow tracts. Note part of the apical aneurysm.

and the subendocardial regions of the left ventricle where foci of fresh muscle necrosis and calcification were seen (Fig. 3).

All the heart valves were of normal appearance. The large arteries and veins were all present and normal in their number and position. The coronaries had normal origins and courses and showed no unexpected changes in calibre or wall thickness. The foramen ovale was patent though small and the ductus arteriosus was open.

\section{Discussion}

Congenital cardiomegaly either familial or idiopathic is well documented (Wood et al., 1962; Krovetz, Gessner, and Schiebler, 1969); it includes obstructive septal hypertrophy, which is known also as hypertrophic subvalvular stenosis and obstructive cardiomyopathy, which though often familial and probably congenital, has only rarely been described in infancy (Neufeld et al., 1960; Krovetz et al., 1969). With regard to infarction and aneurysm in the hearts of babies, a few cases have been described (Ellis, 1935; Franciosi and Blanc, 1968) but not in the association presented here.

The cause of the myocardial apical changes in this case could well be ischaemia due to insufficient blood flow through the coronaries, the altered blood current dynamics and pressures within the ventricle also playing their part. The subendocardial necrosis and calci-

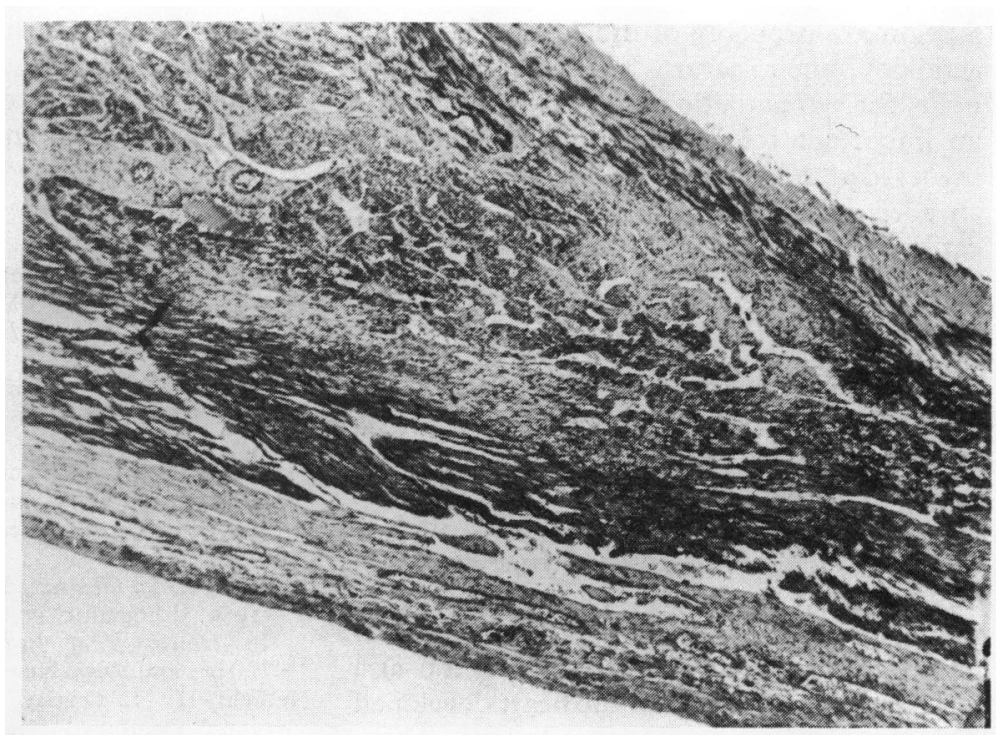

FIG. 2 Myocardium approaching the

aneurysm showing fibrosis, organization, and some fresh necrosis. $(H$. and $E . \times 36$.

FIG. 3 Area of subendocardial muscle with necrosis and calcification. (Alizarin Red $S$ stain. $\times 90$.)

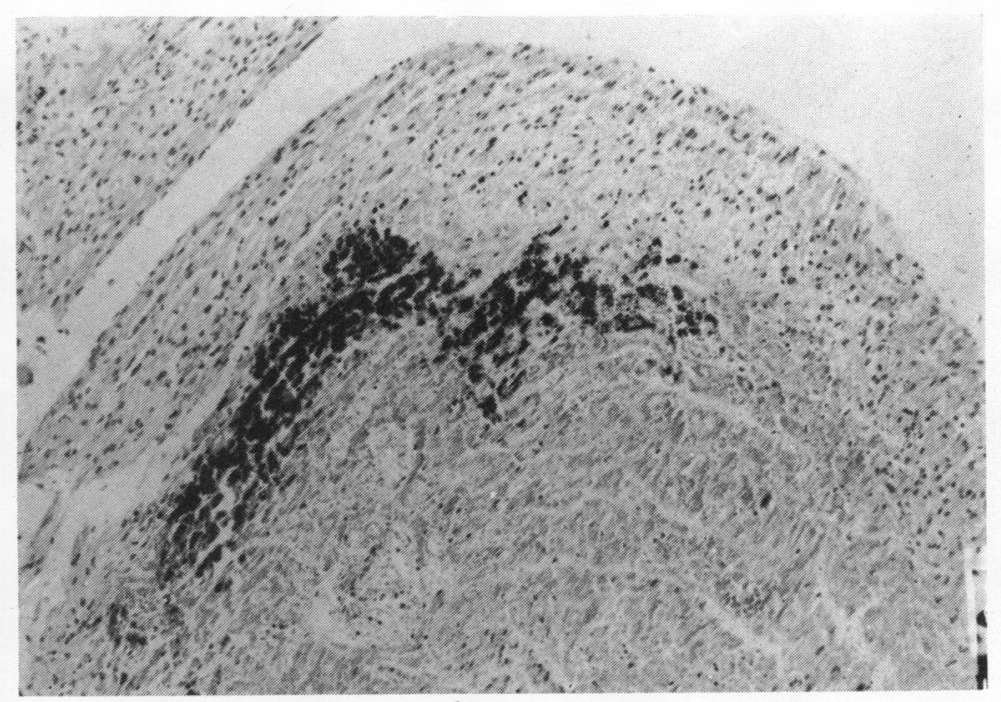


fication are probably of much more complex aetiology, their nature being mainly metabolic, the sympathetic nervous system playing an important role in this, as well as in the myocardial hypertrophy. The possibility of an adrenergic overaction contributing to the cardiac pathology is supported by the similarity of the changes described here to those encountered in hearts of rats treated with isoprenaline, a very sympathomimetic drug (Rona, Kahn, and Chappel, 196I).

In the obstructive type of cardiomyopathy in adults, a 'sympathosis' or increase in the sympathetic nerves especially in the septum is known to occur (Pearse, 1964) and is thought to be of pathogenic significance. It is quite possible that in the case presented here, the brain anomaly included the hypothalamus; an imbalance between the central and local autonomic control of the heart developed with the resulting myocardial lesions. Thus, there may really be a connexion between the anomalies in the heart and in the brain.

An association between the cardiac and renal pathology is more speculative for though congenital anomalies in the two organs together are common, the usual heart condition is an interventricular septum defect. On the other hand, renal changes in a DandyWalker deformity are well known (D'Agostino, Kernohan, and Brown, 1963). This last is transmitted by an autosomal recessive gene, and in the present case the finding of hydrocephalus in 3 out of 6 children suggests strongly a recessive inheritance.

\section{References}

D'Agostino, A. N., Kernohan, J. W., and Brown, J. R. (1963). The Dandy-Walker syndrome. Fournal of Neuropathology and Experimental Neurology, 22, 450.

Ellis, R. W. B. (1935). Infarcts and aneurysm of heart in an infant of nine months. Proceedings of the Royal Society of Medicine, 28, 1333.

Franciosi, R. A., and Blanc, W. A. (1968). Myocardial infarcts in infants and children. I. A necropsy study in congenital heart disease. Fournal of Pediatrics, 73, 309.

Krovetz, L. J., Gessner, I. H., and Schiebler, G. L. (1969). Idiopathic hypertrophic subaortic stenosis. In Handbook of Pediatric Cardiology, p. 303. Harper and Row, New York.

Neufeld, H. N., Ongley, P. A., and Edwards, J. E. (I960). Combined congenital subaortic stenosis and infundibular pulmonary stenosis. British Heart fournal, 22, 686.

Pearse, A. G. E. (1964). The histochemistry and electron microscopy of obstructive cardiomyopathy. In Ciba Foundation Symposium: Cardiomyopathies, pp. 132-164. Ed. by G. E. W. Wolstenholme and M. O'Connor. Churchill, London.

Rona, G., Kahn, D. S., and Chappel, C. I. (I96I). Study on the healing of cardiac necrosis in the rat. American fournal of Pathology, 39, 473.

Wood, R. S., Taylor, W. J., Wheat, M. W., and Schiebler, G. L. (1962). Muscular subaortic stenosis in childhood. Pediatrics, 30, 749. 